\title{
Psychotherapy and Psychosomatics
}

\section{W.A. Lishman}

\section{Organic Psychiatry The Psychological Consequences of Cerebral Disorder; ed 3}

Blackwell, Oxford 1998

922 pp.; $£ 55.00$ (paperback)

ISBN 0-86542-820-4

This the third edition of a classic single-author text that has become the standard reference for clinicians working at the interface between psychiatry and medicine. The second edition was released in 1987. The third edition is not only updated, but includes new topics, such as the neuropsychiatric aspects of schizophrenia. As a result, even those who own the previous edition are urged to purchase the new one. Lishman's ability to capture the essential clinical features of organic mental disorders is unsurpassed.

A.J. Gelenberg, E.L. Bassuk (eds)

\author{
The Practitioner's Guide to Psychoactive \\ Drugs; ed. 4 \\ Plenum, New York 1997 \\ $536 \mathrm{pp}$. \\ ISBN 0-300-45468-8
}

Four editions of a guide are themselves a proof of its clinical usefulness. And, indeed, this updated edition is another outstanding survey of the clinical use of psychotropic drugs. The introduction by Alan Gelenberg on the practice of pharmacotherapy sets the balanced, cautious tone of the volume. It should become a required reading in residency training programs. The clinical use of psychotropic drugs in depression, bipolar disorders, psychoses, anxiety, insomnia, drug dependence, geriatric and pediatric psychopharmacology, pregnancy, HIV disorders, eating disorders and borderline disturbances is critically examined. What is remarkable, is the selection of clinically relevant information. The last chapter on the medicalegal aspects of pharmacology is of considerable interest, even outside of the US. No clinician using psychotropic drugs can afford missing this guide.

\section{R.P. Swinson, M.M. Anthony, S. Rachman, M.A. Richter (eds)}

\section{Obsessive Compulsive Disorders Theory, Research and Treatment}

\author{
Guilford Press, New York 1998 \\ $478 \mathrm{pp}$.
}

ISBN 1-573230-335-2

This is probably the most comprehensive and balanced survey of this illness available. It is divided into three parts. The first deals with psychopathology and theoretical perspectives (epidemiology, psychotherapy, drug treatment, obsessive-compulsive disorder in children and adolescents). The second part is concerned with assessment and treatment (encompassing psychotherapy, drug treatment and obsessive-compulsive disorder in children and adolescents). The third part is largely speculative and deals with conceptual foundations of obsessive-compulsive disorders. The first two parts offer an outstanding appraisal of the state of the art of the field and how these insights translate into the clinical approach.

R. Noyes, R. Hoehn-Saric

\section{The Anxiety Disorders}

\author{
Cambridge University Press, Cambridge 1998 \\ 343 pp.; $£ 45.00$ \\ ISBN 0-521-55207-9
}

This book offers a good synthesis of biological insight and phenomenological appraisal of anxiety disorders by two leading researchers in the field. It opens with an excellent chapter on normal anxiety and fear, and subsequently deals with the various anxiety disorders. The last chapter is concerned with anxiety disorders in the medically ill, which may be particularly helpful to consultation-liaison psychiatrists. Unfortunately, there are major omissions in psychological treatment of anxiety disorders (for instance, the LondonToronto Study on panic disorder is not even cited). These omissions make several treatment recommendations misleading and not in line with current research evidence.

\section{KARGER}

(c) 1999 S. Karger AG, Basel

Fax +41613061234

E-Mail karger@karger.ch www. karger.com
Accessible online at: http://BioMedNet.com/karger 